\title{
Effects of Buckling Knockdown Factor, Internal Pressure and Material on the Design of Stiffened Cylinders
}

\author{
Andrew E. Lovejoy ${ }^{*}$, Mark W. Hilburger ${ }^{\dagger}$ \\ NASA Langley Research Center, Hampton, VA 23681 \\ and \\ Prasad B. Chunchu ${ }^{\ddagger}$ \\ Eagle Aeronautics, Inc., Hampton, VA 23669
}

\begin{abstract}
A design study was conducted to investigate the effect shell buckling knockdown factor (SBKF), internal pressure and aluminum alloy material selection on the structural weight of stiffened cylindrical shells. Two structural optimization codes were used for the design study to determine the optimum minimum-weight design for a series of design cases, and included an in-house developed genetic algorithm (GA) code and PANDA2. Each design case specified a unique set of geometry, material, knockdown factor combinations and loads. The resulting designs were examined and compared to determine the effects of SBKF, internal pressure and material selection on the acreage design weight and controlling failure mode. This design study shows that use of less conservative SBKF values, including internal pressure, and proper selection of material alloy can result in significant weight savings for stiffened cylinders. In particular, buckling-critical cylinders with integrally machined stiffener construction can benefit from the use of thicker plate material that enables taller stiffeners, even when the stiffness, strength and density properties of these materials appear to be inferior.
\end{abstract}

\section{Nomenclature}

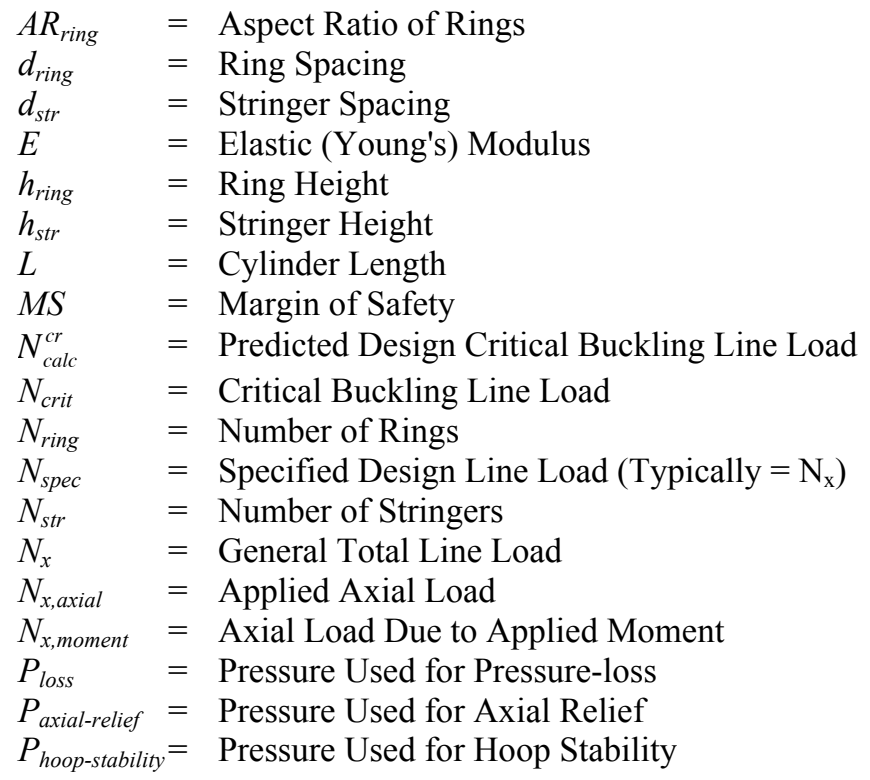

\footnotetext{
${ }^{*}$ Aerospace Engineer, Structural Mechanics \& Concepts Branch, MS 190, Senior Member AIAA, Member ASME.

$\dagger$ Aerospace Engineer, Structural Mechanics \& Concepts Branch, MS 190, Senior Member AIAA.

${ }^{\ddagger}$ Research Engineer, 13 West Mercury Boulevard, Member AIAA. 


\section{Tracking \#210774}

$\begin{array}{ll}P_{\max } & =\text { Maximum Pressure } \\ P_{\text {proof }} & =\text { Proof Pressure } \\ P_{\text {ullage }} & =\text { Ullage Pressure } \\ p s i & =\text { Pounds per Square Inch } \\ R & =\text { Radius of Cylinder } \\ S F & =\text { Safety Factor } \\ t_{\text {ring }} & =\text { Thickness of Rings } \\ t_{s} & =\text { Cylinder Shell Skin Thickness } \\ t_{\text {skinmin }} & =\text { Minimum Allowable Shell Skin Thickness } \\ t_{\text {str }} & =\text { Thickness of Stringers } \\ \Delta \gamma & =\text { Increment in Shell Buckling Knockdown Factor Due to Internal Pressure } \\ \gamma & =\text { Shell Buckling Knockdown Factor } \\ \gamma_{\text {loss }} & =\text { Shell Buckling Knockdown Factor for Pressure Load Case } \\ \rho & =\text { Weight Density } \\ v & =\text { Poisson's Ratio } \\ \sigma_{\text {allow }} & =\text { Allowable Stress } \\ \sigma_{\text {calc }} & =\text { Calculated Stress } \\ \sigma_{u} & =\text { Material Ultimate Stress } \\ \sigma_{y} & =\text { Material Yield Stress }\end{array}$

\section{Introduction}

$\mathrm{M}$ any components of launch vehicles consist of stiffened cylindrical structures, and these components may or may not be pressurized. Typical design practice for these cylinders uses conservative shell buckling knockdown factor (SBKF) values that are used to account for the differences that have been observed between test and theory. Recommended SBKF values for typical launch vehicle structure can be obtained from several sources, including references 1-3. Unfortunately, the pedigree of the test data, that typically dates from the 1930s to 1960s, is not well known, and in some cases (see ref. 3) does not account for pressure stabilization or length. As a result, conservative designs are developed that lead to weight penalty in a structure that is weight critical. In order to develop more efficient and effective launch vehicles, it is desirable to update the design process by developing less conservative SBKF values, and to account for pressure stabilization and for a variety of material and constraint types.

As a first step in determining SBKF technology development priorities, a design study was conducted to investigate the portions of the typical design approach that can be improved to yield more structurally efficient cylinder designs for launch vehicle structure. The study used both an in-house developed genetic algorithm (GA) code and PANDA2 ${ }^{4}$ to examine unpressurized and pressurized cylinder designs. SBKF values were varied for both sets of designs, and pressure stabilization was also included. Additionally, inclusion of material constraints for related aluminum alloys demonstrates the importance of taking material size limitations into account in the design process for these cylinders. Optimum area weights for the study designs are examined and compared to show that use of less conservative SBKF values, including internal pressure, and proper selection of material alloy can result in significant weight savings for stiffened cylinders.

\section{Physical Description of the Structure}

Various cylinders with integrally machined orthogrid wall construction were considered in this study. Each cylinder section represents the uniform acreage design. No cutouts, weld land or additional structural details were accounted for in the design process. Definitions of the orthogrid geometry parameters are shown in Figure 1. The study considered three aluminum alloys that are defined in the following section. Designs were chosen that were considered to be typical of current launch vehicle structure. Unpressurized cylinders in this study had 200-inch radius and pressurized cylinders had 100-inch radius. Cylinder length (L) to radius ratios (L/R) of 0.5 and 0.75 for unpressurized cylinders and $\mathrm{L} / \mathrm{R}$ of 1.5 for pressurized cylinders were used in this study. The cylinders were assumed to be simply supported on both ends. Applied loads are described subsequently, and consisted of uniform axial line load and internal pressure. 


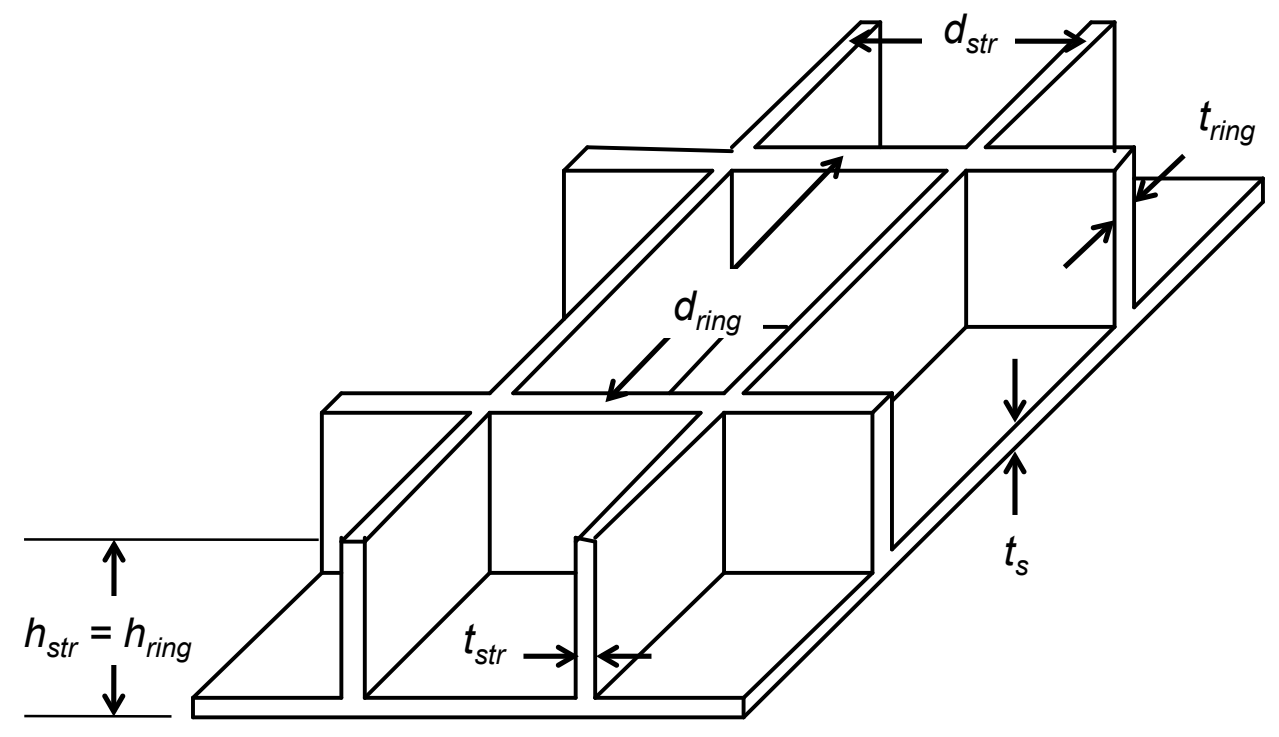

Figure 1: Orthogrid geometry parameters.

\section{Material Properties}

The orthogrid cylinder designs utilized aluminum alloys whose properties were obtained from manufacturer data sheets ${ }^{5,6}$ or MMPDS- $04^{7}$. Room temperature properties were used throughout the design study. Material information used in the design study for the three alloys used is shown in Table 1. All three alloys, 2195-T8R78 (2195), 2050T84 (2050) and 2219-T851 (2219), were use in the unpressurized designs, while only alloy 2195 was used in the pressurized designs.

Table 1: Aluminum alloy material properties.

\begin{tabular}{|l|c|c|c|}
\hline \multicolumn{1}{|c|}{ Property } & 2195-T8R78 $^{\mathbf{5}^{2}}$ & $\mathbf{2 0 5 0 -}^{-\mathbf{T 8 4}^{\mathbf{6}}}$ & 2219-T851 $^{\mathbf{7}}$ \\
\hline $\mathrm{E}(\mathrm{Msi})$ & 11.0 & 11.1 & 10.6 \\
\hline$\sigma_{\mathrm{y}}(\mathrm{ksi})$ & 73.0 & 71.0 & 51.0 \\
\hline$\sigma_{\mathrm{u}}(\mathrm{ksi})$ & 81.0 & 75.0 & 66.0 \\
\hline$\rho\left(\mathrm{lb} / \mathrm{in}^{3}\right)$ & 0.098 & 0.098 & 0.103 \\
\hline$v$ & 0.33 & 0.33 & 0.33 \\
\hline Max. Plate Thickness (in.) & 1.8 & 4.8 & 5.8 \\
\hline
\end{tabular}

\section{Loads}

Several load cases were considered for each of the stiffened cylinder designs, and include axial loads and/or pressure loads. The total axial load used for each load case represents the sum of an applied axial load and the maximum compressive contribution of an applied bending moment, and was assumed to be uniform around the cylinder circumference. This simplification was adopted as it is considered to represent the approach that is used in preliminary design. The total axial load is thereby defined by:

$$
N_{x}=N_{x, \text { axial }}+\max \operatorname{comp}\left(N_{x, \text { moment }}\right)
$$

Load cases considered in this study include those that would represent proof pressure, pre-launch, flight and a fail-safe pressure-loss load case. Proof pressure is a load case whereby a pressurized tank component must sustain a prescribed pressure without yielding. The pre-launch load case represents the load while a launch vehicle is on the launch pad prior to applying the ullage pressure in tank components, and is subjected to wind loads and structural weight. The flight load case represents the worst loads experienced during the flight profile, and for unpressurized cylinders this was the only load case applied. Lastly, the pressure-loss load case represents a hypothetical fail-safe flight load case where the ullage pressure is reduced to some prescribed level and global buckling is not permitted 
prior to limit load $(\mathrm{SF}=1.1)$. This approach is used in designs that consider pressure stabilization. The proof load case was used prior to optimization to determine the minimum skin thickness for pressurized cylinders by requiring that the skin sustain the proof hoop stress without yielding. Mathematically, this is given by:

$$
t_{\text {skin, } \min }=\frac{p_{\text {proof }} R}{\sigma_{y}}
$$

where $t_{s k i n, \text { min }}$ is the minimum skin thickness, $P_{\text {proof }}$ is the proof pressure, $R$ is the cylinder radius and $\sigma_{y}$ is the yield stress of the material. In this study, $P_{\text {proof }}=66 \mathrm{psi}$, resulting in a minimum skin thickness of 0.09 inches

Unpressurized cylinders were optimized under flight loads of $N_{x}=-1800$ and $-2000 \mathrm{lb} / \mathrm{in}$. Load case definitions for the pressurized cylinders are shown in Table 2 . In the pressure-loss case $P_{\text {loss }}=0.0$ psi, optimization was performed for three load set combinations; 1) $\left.P_{\text {relief }}=P_{\text {hoop-stability }}=0.0 \mathrm{psi}, 2\right) P_{\text {axial-relief }}=20.0 \mathrm{psi}$ and $P_{\text {hoop-stability }}=$ $0.0 \mathrm{psi}$, and 3) $P_{\text {asial-relief }}=P_{\text {hoop-stability }}=20.0 \mathrm{psi}$. Maximum and ullage pressures were assumed to be $P_{\max }=50.0 \mathrm{psi}$ and $P_{\text {ullage }}=30.0 \mathrm{psi}$ in the flight load case for stress calculations in the pressurized cylinders. Only aluminum alloy 2195-T8R78 was used in the pressurized cylinder portion of the study.

Table 2: Load case definitions for pressurized cylinders.

\begin{tabular}{|l|c|c|c|c|}
\hline \multicolumn{1}{|c|}{ Load Case } & Nx (lb/in) & $\mathbf{P}_{\text {axial-relief }}(\mathbf{p s i})$ & $\mathbf{P}_{\text {hoop-stability }}(\mathbf{p s i})$ & $\mathbf{P}_{\text {loss }}(\mathbf{p s i})$ \\
\hline Prelaunch & -800 & 0.0 & 0.0 & $\mathrm{~N} / \mathrm{A}$ \\
\hline Flight & -3200 & $0.0,20.0$ & $0.0,20.0$ & $\mathrm{~N} / \mathrm{A}$ \\
\hline & & & & $0.0,1.0,2.0,4.0$, \\
Pressure-loss & -3200 & $P_{\text {loss }}$ & $P_{\text {loss }}$ & $6.0,10.0,20.0$ \\
\hline
\end{tabular}

\section{Design Requirements and Criteria}

\section{Structural Design}

Designs were developed using two different optimization codes to determine the sizing of the various orthogrid geometry parameters shown in Figure 1. Numerous design constraints were assigned that are categorized as failure constraints and geometry constraints. Failure constraints included;

- Global buckling

- Local buckling (see ref. 8)

- Limit strength (unidirectional in axial and circumferential directions)

- Limit stress (bi-axial)

- Ultimate strength (unidirectional in axial and circumferential directions)

- Ultimate stress (bi-axial)

- Stiffener buckling (PANDA2 only)

- $\quad$ Stiffener crippling (see ref. 9, GA only)

- Crippling/buckling interaction (see ref. 9, GA only)

Geometry constraints included;

- Shell thickness (in.) $\left(\mathrm{t}_{\text {skin,min }} \leq \mathrm{t}_{\mathrm{s}} \leq 0.40\right.$ in.)

- Pressurized: $t_{\text {skin,min }}$ derived from proof pressure, $0.09 \mathrm{in}$.

○ Unpressurized: $t_{\text {skin,min }}$ derived from minimum manufacturing gauge of $0.065 \mathrm{in}$.

- Stringer spacing (2.0 in. $\leq \mathrm{d}_{\mathrm{str}} \leq 16.0$ in.)

- Stringer thickness (in.) $\left(0.065\right.$ in. $\leq \mathrm{t}_{\mathrm{str}} \leq 1.0$ in. $)$

- Ring spacing (2.0 in. $\leq \mathrm{d}_{\mathrm{str}} \leq 50.0$ in.)

- Ring thickness (in.) $\left(0.065\right.$ in. $\leq \mathrm{t}_{\text {ring }} \leq 1.0$ in. $)$

- Ring aspect ratio $\left(0.0 \leq \mathrm{AR}_{\text {ring }} \leq 12.0\right)$

$\circ$ Manufacturing constraint due to forming process

- $\quad$ Stringer height $=$ Ring height

- Minimum stringers per circumferential wave number, $\mathrm{n}=10$

$\circ$ GA only, to justify the use of smeared stiffener approximation

- Maximum plate stock thickness (material alloy dependent, see Table 1) 


\section{Tracking \#210774}

Only internal stiffeners were considered in the current study, and the height of the stiffeners is defined as the distance from the outer mold line to the top of the stiffener. The minimum and maximum limits for the stringer and ring spacing were arbitrarily chosen for the design study. The ring aspect ratio, $\mathrm{AR}_{\text {ring, }}$, is the ring height divided by the ring thickness, $h_{\text {ring }} / t_{\text {ring, }}$, with the maximum limit value of 12.0 being set by manufacturing constraints.

\section{Safety and Knockdown Factors}

Relevant safety factors and knockdown factors for this type of structure were used in the design process. The safety factors apply to all design loads and include limit stress, ultimate stress, global buckling and local buckling. Knockdown factors for global buckling are applied to account for reduction in predicted buckling load due to geometric imperfections. The baseline value for the shell buckling knockdown factor for stiffened shells, $\gamma=0.65$, was obtained from the Isogrid Design Handbook ${ }^{3}$. Larger magnitude shell buckling knockdown factors are used in pressurized cylinders to account for the fact that internal pressure reduces the sensitivity of the buckling load to initial geometric imperfections. This increase, $\Delta \gamma$, is dependent upon the internal pressure of the cylinder. The $\Delta \gamma$ values used for the pressurized cylinders were developed from an imperfection sensitivity study for pressurized cylinders using the STAGS ${ }^{10}$ finite element code. These analysis-based $\Delta \gamma$ values are smaller in magnitude than would be obtained using the method described in SP- $8007^{1}$, however, they represent a conservative estimate of the potential benefit of reduced imperfection sensitivity associated with pressurized cylinders. The study was begun using the baseline shell buckling knockdown factor of $\gamma=0.65$. This value was then increased to $\gamma=0.75$ and $\gamma=$ 0.85 . The SBKF for pressurized load cases was then increased by $\Delta \gamma=0.14$ when pressure stabilization was included for the cylinders being studied. The SBKF for the pressure-loss load case was linearly interpolated between the unpressurized SBKF and the pressure-stabilized SBKF. Mathematically, this is represented by:

$$
\gamma_{\text {loss }}=\gamma+\Delta \gamma\left(\frac{P_{\text {loss }}}{P_{\text {hoop-stability }}}\right)
$$

A local buckling knockdown factor of 0.9 was chosen, and is considered to be very conservative.

The safety factors applied to the design cases in this study are as follows;

- $\quad$ Limit $=1.1$

- $\quad$ Ultimate $=1.4$

- $\quad$ Global buckling $=1.4$

$\circ$ Reduced to 1.1 or 1.2 in pressure-loss case for pressurized cylinders

- $\quad$ Local buckling $=1.25$

\section{Margin Calculations}

Margins of safety (MS) were calculated based upon allowable values or design requirements. A generic form of the MS calculation equation is:

$$
M S=\frac{\text { Specified_Value }}{\text { Calculated_Value }}-1
$$

For a stress margin of safety, the calculation was performed using the following equation:

$$
M S=\frac{\sigma_{\text {allow }}}{S F\left(\sigma_{\text {calc }}\right)}-1
$$

where SF represents the applicable safety factor, $\sigma_{\text {allow }}$ is the allowable stress $\left(\sigma_{\mathrm{y}}\right.$ for limit load and $\sigma_{\mathrm{u}}$ for ultimate load), and $\sigma_{\text {calc }}$ is the calculated stress. The buckling margin of safety calculations include the appropriate knockdown factor as given in the following equation:

$$
M S=\frac{\gamma\left(N_{\text {calc }}^{c r}\right)}{S F\left(N_{\text {spec }}\right)}-1
$$


where $\gamma$ is the knockdown factor, $N_{\text {calc }}^{c r}$ is the predicted critical buckling line load for a given design, and $N_{\text {spec }}$ is the specified design line load. The design study required that all calculated MS be greater than or equal to zero.

\section{Design Approach}

Designs for the cylinders were obtained by using two different optimization design codes, a genetic algorithm (GA) based code and PANDA2 ${ }^{4}$. The GA code was developed in-house by linking a GA with BOSOR4 ${ }^{11}$, where BOSOR4 was used to determine global buckling loads and mode shapes. Stiffeners, rings and stringers for the designs were approximated using a smeared stiffener approach in the global buckling analyses. Additional constraint calculations in the GA code, such as allowable stress, local buckling and crippling, are similar to those used in other commercially-available design codes and handbooks. For the GA, ten random number seeds were used to initiate ten optimization analyses for each design, and the best solution was chosen as the minimum weight design that satisfied all the design constraints. PANDA2 is a panel optimization code that also uses BOSOR4. For this study, a single PANDA2 optimization analysis was used, with three or four superopt ${ }^{4}$ executions being conducted for each design. It should be noted that PANDA2 has built-in constraints additional to those discussed in Section III.

PANDA2 permits only one material stress allowable, so an additional load case was required to examine both yield and ultimate stress constraints. The additional PANDA2 stress load case was only applied to the flight load case since it was assumed that the other load cases resulted in equal or lower stresses, and therefore, the role of stress in the design was accounted for in the flight load case. At the same time, the buckling knockdown factors for this additional load case were increased because buckling was already being addressed by the original flight load case. The separate yield and ultimate stress analysis capability is included for each load case in the GA code by accepting both yield and ultimate stress allowable values.

\section{Results}

Area weight results for unpressurized orthogrid cylinders are shown in Figures $2-5$. It is seen that the results for the GA and PANDA2 2195 designs are in very good agreement for area weight and weight reduction trend. In contrast, the designs for 2050 and 2219 show good agreement for weight reduction trend, but show significant difference in area weights. This difference likely arises from the fact that PANDA2 has additional constraints and additional conservatism applied to the design compared to the GA code. For example, for the 2219 design weights shown in Figure 2 with $\gamma=0.65, N_{x}=-1800 \mathrm{lb} / \mathrm{in}$., and $\mathrm{L} / \mathrm{R}=0.5$, the GA and PANDA2 designs have area weights of 2.05 and $2.68 \mathrm{lb} / \mathrm{ft}^{2}$, respectively. Examination of the constraints show that both consider global buckling and local buckling as design drivers, with both having MS of near zero. The PANDA2 design has an additional constraint, lateral buckling on the stiffener, that also has an MS of nearly zero. This constraint is not included in the GA code. As a result, the stiffener height in the GA design is 2.23 in. as compared to 1.87 in. for the PANDA2 design. Similarly, the stringer aspect ratio is much larger for the GA design than the PANDA2 design. Therefore, the GA code allows for a stiffener that is much more efficient when it comes to global buckling, but violates a constraint that is included in PANDA2. This discovery suggests that these constraints should be investigated further and the GA code modified as necessary. However, the current study is concerned with the trends in weight reduction, and the designs from the two codes show very good agreement in this respect.

It is seen in the Figures $2-5$ that for the 2195 designs, there is significant weight reduction when the SBKF is increased from 0.65 to 0.85 , with area weight reductions on the order of 18 to 24 percent. However, compared to the 2195 designs, area weight reductions for the 2050 and 2219 alloys are significantly smaller, on the order of 4 to 13 percent for the same range of SBKF values, and are much more uniform across the range. These trends are due to the fact that the smaller plate stock thickness of the 2195 alloy imparts a weight penalty resulting from the materialinduced stiffener height constraint. As a result, the designs use the entire available plate thickness, and the thicknesses of the stringers and rings are required to be much thicker in order to provide the required bending stiffness necessary to resist global buckling. Contrary to this, the designs for the 2050 and 2219 alloys take advantage of the increased material thickness by developing taller stiffeners, but never approach requiring the entire plate thickness.

The GA results in Figures $2-5$ show clear separation in the area weight of the designs for the three alloys. However, the PANDA2 results suggest that the 2050 designs result in minimum weight for all SBKF values in this study, but for 2195 and 2219 the minimum weight cylinder is dependent upon the SBKF value. Consider the 2219 design weights shown in Figure 3 with $\gamma=0.65, N_{x}=-2000 \mathrm{lb} / \mathrm{in}$., and $\mathrm{L} / \mathrm{R}=0.5$, where the GA and PANDA2 designs have area weights of 2.15 and $2.86 \mathrm{lb} / \mathrm{ft}^{2}$, respectively, while the corresponding 2195 designs have GA and PANDA2 area weights of 2.87 and $3.00 \mathrm{lb} / \mathrm{ft}^{2}$, respectively. Despite 2219 having a density that is 5.1 percent higher than 2195, while at the same time having a stiffness (modulus) and a strength allowable (yield) that are 3.6 and 30 
percent lower than 2195, respectively, both codes yield 2219 designs that result in reduced weight compared to 2195. Weight savings predicted by the GA and PANDA2 for these designs are 25 percent and 4.7 percent, respectively. The reduced savings for the PANDA2 designs is attributed to the aforementioned additional constraints included in PANDA2. Next, for $N_{x}=-2000 \mathrm{lb} / \mathrm{in}$. and $\mathrm{L} / \mathrm{R}=0.5$, but with $\gamma$ increased from 0.65 to 0.85 , PANDA2 yields a 2195 design that is 7.2 percent lower than the corresponding 2219 design. This switch in optimum material results from the lower stiffness of the 2219 having a greater impact on the stiffener lateral buckling constraint in PANDA2. Therefore, depending on the design code used and the active constraints for the design, it is possible that material selection should become a design variable in order to obtain minimum weight designs.

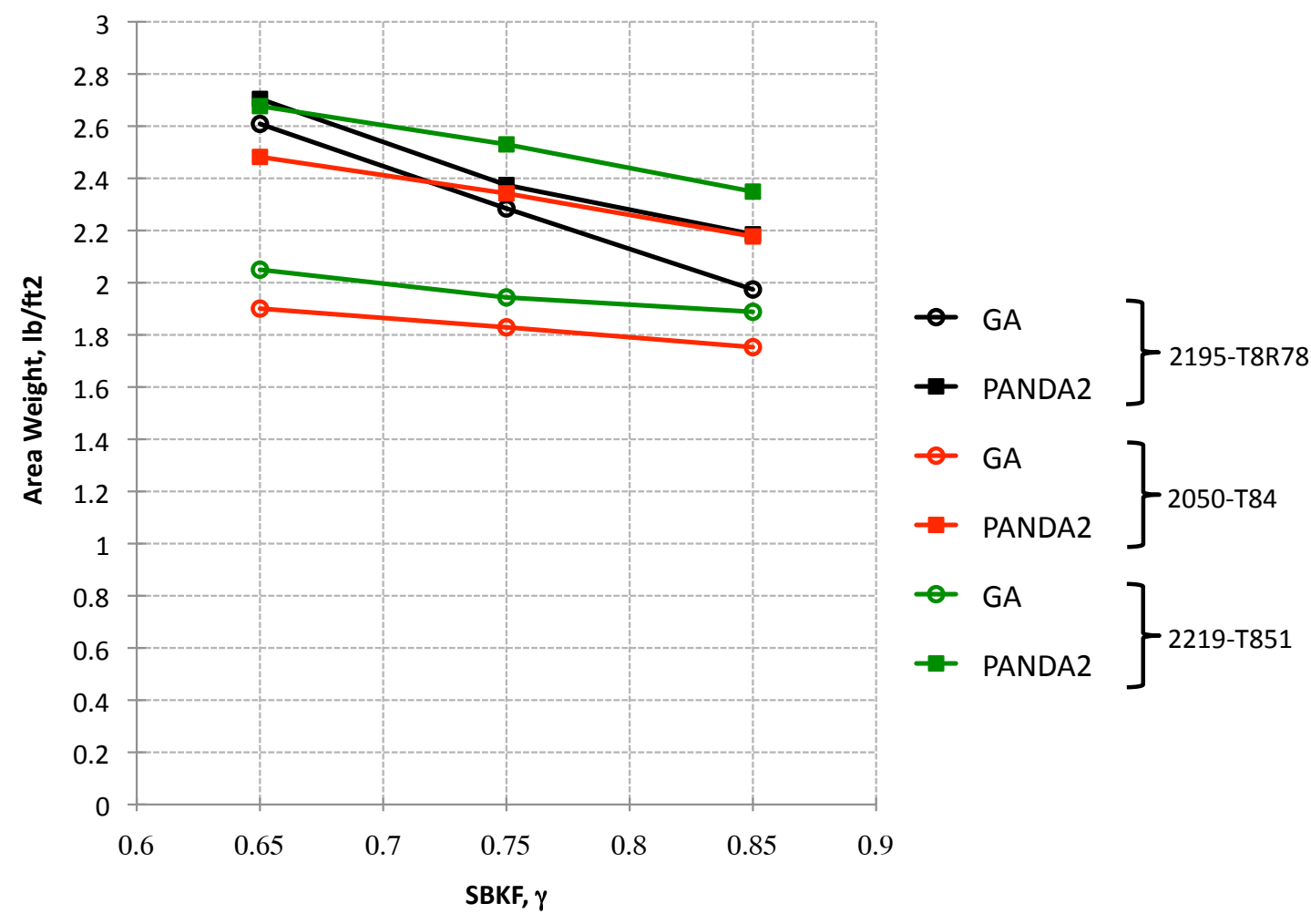

Figure 2: Area weight of unpressurized, orthogrid cylinder; $N_{x}=-1800 \mathrm{lb} / \mathrm{in}$., $\mathrm{L} / \mathrm{R}=0.5$. 
Tracking \#210774

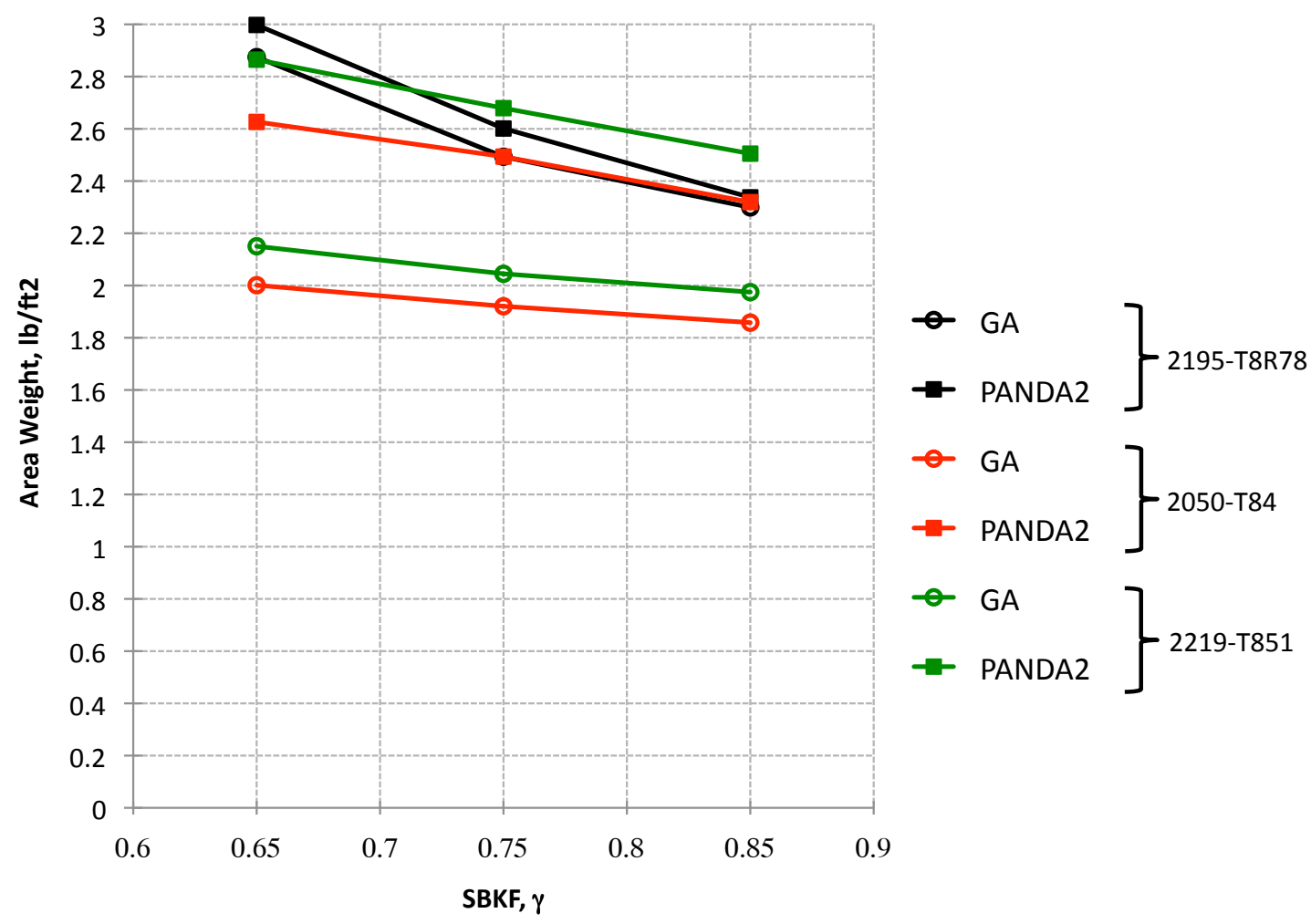

Figure 3: Area weight of unpressurized, orthogrid cylinder; $N_{x}=-2000 \mathrm{lb} / \mathrm{in} ., \mathrm{L} / \mathrm{R}=0.5$.

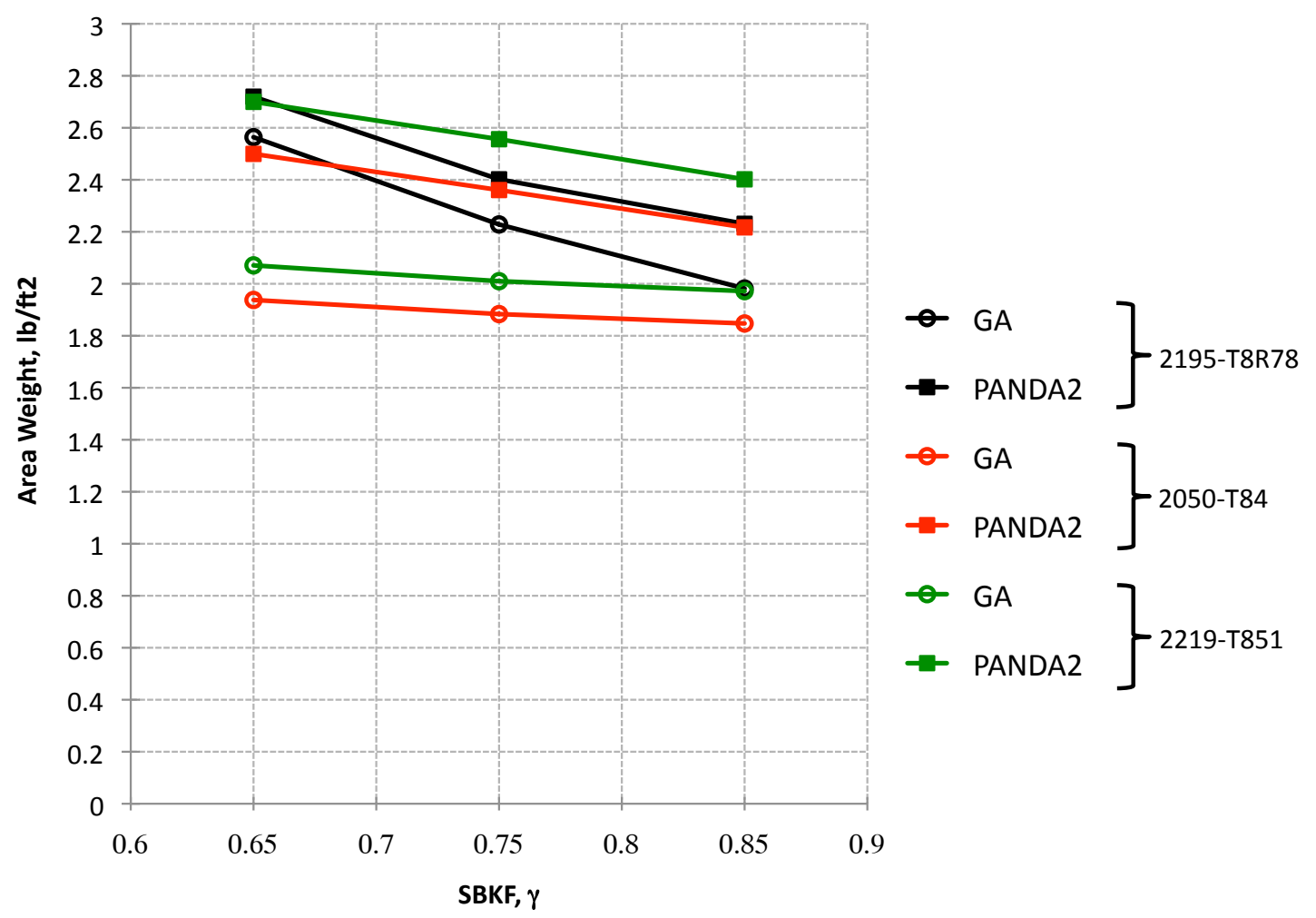

Figure 4: Area weight of unpressurized, orthogrid cylinder; $N_{x}=-1800 \mathrm{lb} / \mathrm{in} ., \mathrm{L} / \mathrm{R}=0.75$. 


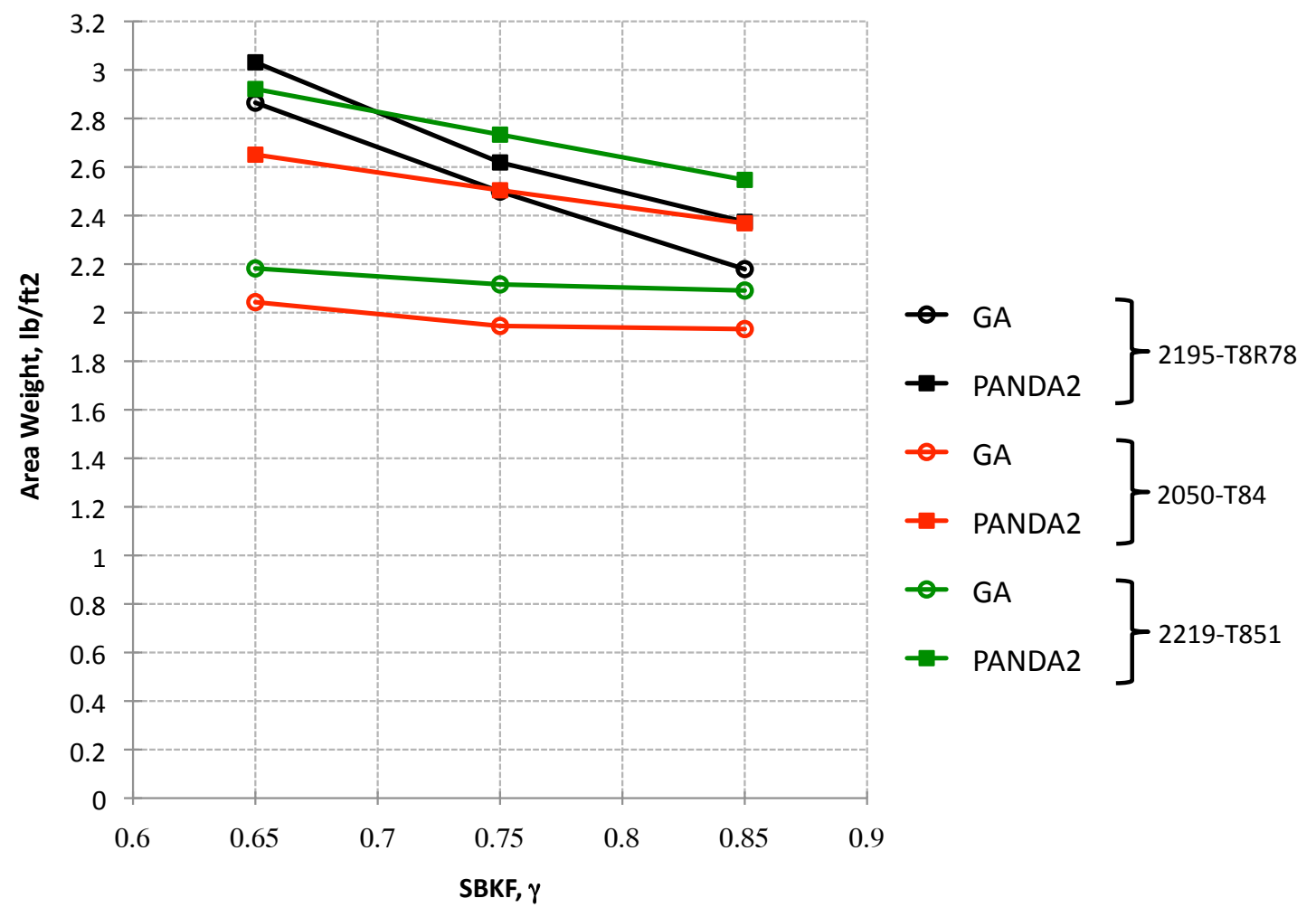

Figure 5: Area weight of unpressurized, orthogrid cylinder; $N_{x}=-2000 \mathrm{lb} / \mathrm{in} ., \mathrm{L} / \mathrm{R}=0.75$.

Area weight results for pressurized, orthogrid cylinders fabricated from 2195 alloy are shown in Figures $6-8$. Results for the pressure-loss load case with global buckling SF $=1.1$ and 1.2 are shown in Figures 6 and 7, respectively. These figures also show the area weight for when no pressure relief or stabilization is included in the design for the typical approach where $\gamma=0.65$ (black circles). Also shown is the case where pressure relief is included but pressure stabilization and pressure-loss load case are not, and where $\gamma=0.65$ (black squares). When pressure stabilization is included, the pressure-loss load case becomes the design driver up until the reduced internal pressure reaches a certain value, as indicated by an abrupt change in slope on the plots. As seen in the figures, the pressure value at which the controlling load case transitions from the pressure-loss load case to the flight load case is a function of global buckling SF in the pressure-loss load case. Above this transition pressure, the pressure-loss load case no longer affects the design. For example, changing the global buckling SF value from 1.1 to 1.2 changes this transition pressure value from about 12.5 psi to about 14 psi.

Maximum weight savings can be obtained by including pressure relief and stabilization, and by omitting the failsafe pressure-loss load case, with area weight reductions of 36 to 41 percent for SBKF values from 0.65 to 0.85 . When including the pressure-loss load case, where the internal pressure is reduced to $0.0 \mathrm{psi}$, the weight reductions range from 8.5 to 24 percent. Next, a comparison of the area weights as a function of the global buckling SF in the pressure-loss load case is shown in Figure 8 for $\gamma=0.65$. It is clear that increasing the SF value will result in a reduction in weight savings. Judicious choice of global buckling SF and reduced internal pressure in a pressure-loss load case can result in significant weight reduction when compared to an unpressurized design, while providing for various fail safe options. 


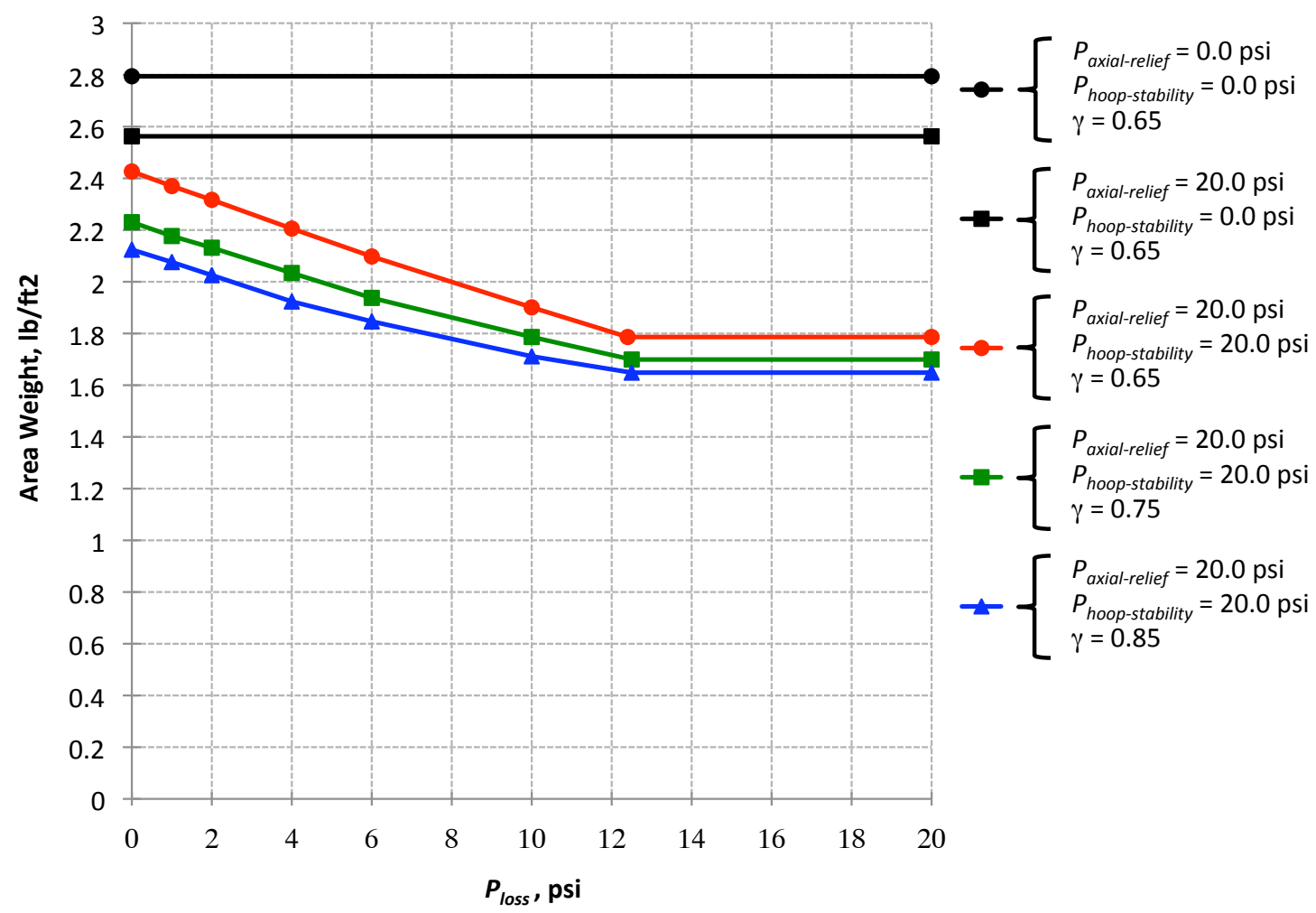

Figure 6: Effect of pressure-loss load case $P_{\text {loss }}$ value on area weight of pressurized cylinder, PANDA2 results; pressure-loss load case global buckling $S F=1.1$.

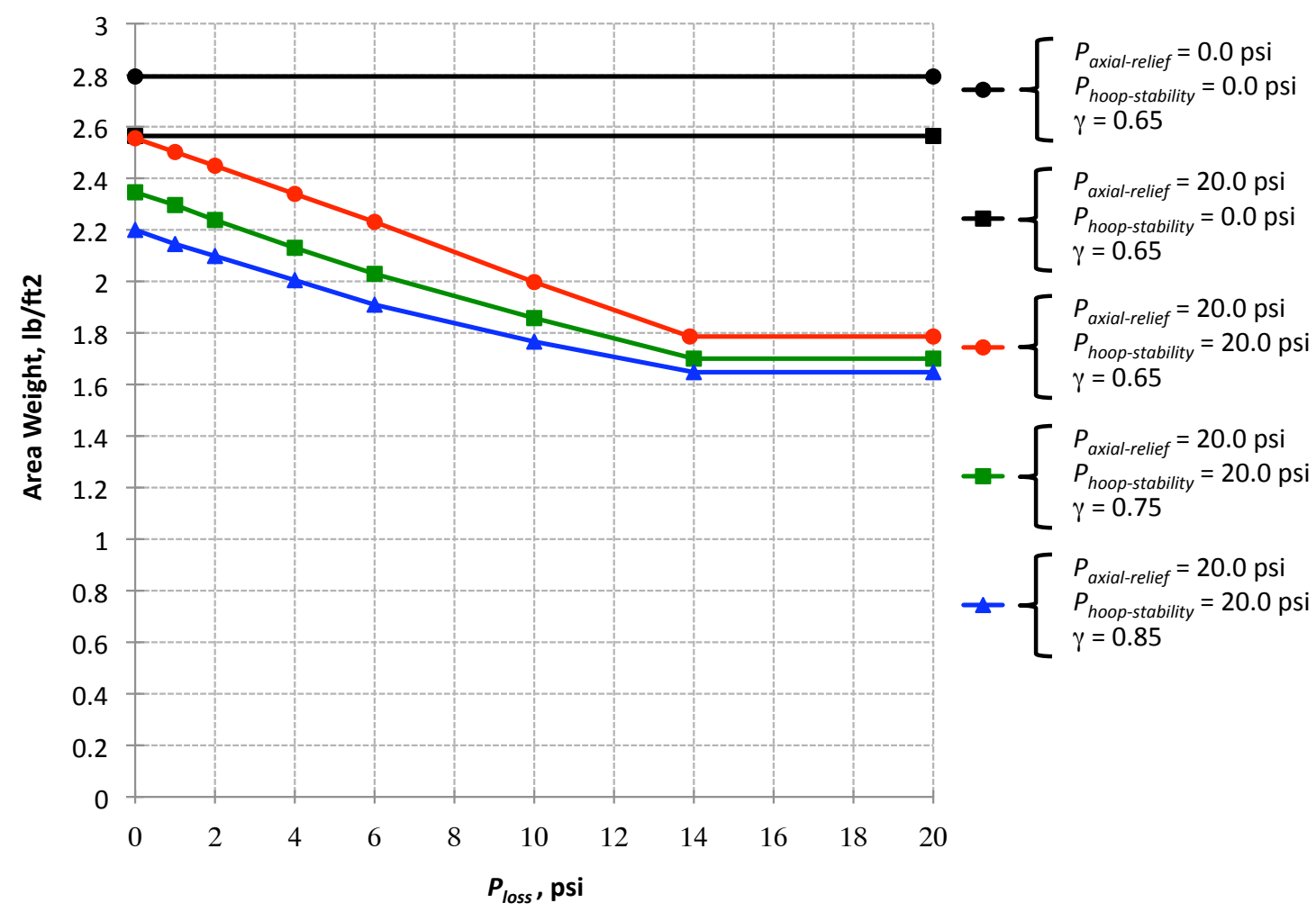

Figure 7: Effect of pressure-loss load case $P_{\text {loss }}$ value on area weight of pressurized cylinder, PANDA2 results; pressure-loss load caseglobal buckling $S F=1.2$. 


\section{Tracking \#210774}

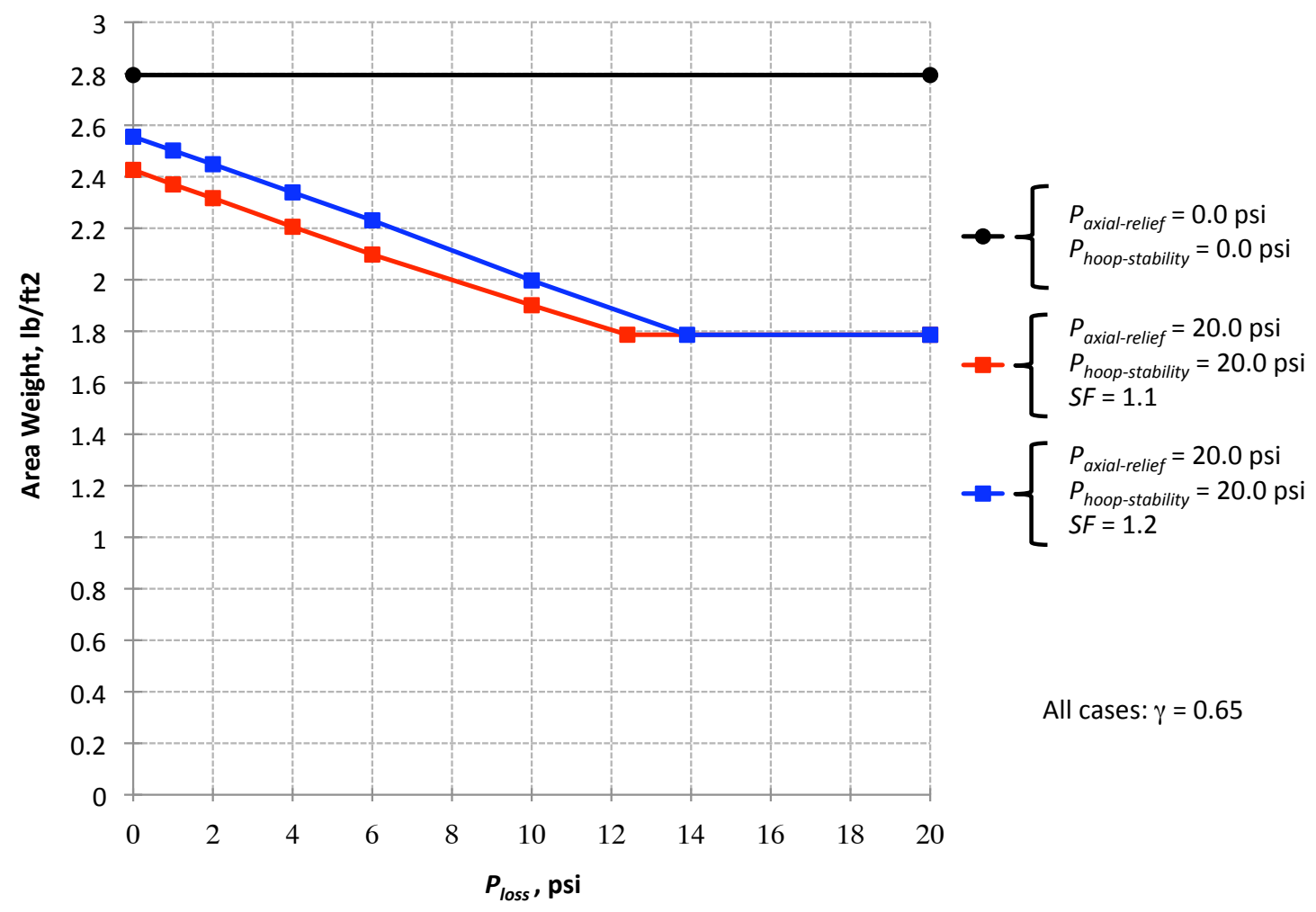

Figure 8: Effect of pressure-loss load case global buckling $S F$ value on area weight of pressurized cylinder, PANDA2 results; $\gamma=0.65$.

\section{Conclusion}

The stiffened cylinder designs in the current study were examined to determine the effects of the SBKF, internal pressure and material selection on the optimized design weight. Weight comparison was based upon a traditional approach without pressure relief or stabilization. In particular, it was shown that SBKF and internal pressure can have a significant effect on the design weight of buckling-critical designs. For example, weight reductions approaching 41 percent were achieved by using a higher SBKF, and by including hoop stabilization due to internal pressure, which accounts for the stabilizing hoop stress and an additional increase in SBKF Including a pressure-loss load case to provide a fail-safe condition results in a lower weight savings. This weight savings is dependent upon the global buckling SF and reduced internal pressure used in the pressure-loss load case. However, based on the typical design approach, including a pressure-loss load case can still yield significant weight savings. Additionally, for unpressurized cylinders, selection of a material that is manufactured in thicker stock can provide a significant weight savings. This weight savings is expected to be applicable to pressurized cylinders, as well. These observations lead to three general conclusions:

1. Reasonable increases in SBKF, from $\gamma=0.65$ to $\gamma=0.75$ or 0.85 , can result in lower cylinder design weights. Therefore, it would be advantageous to develop less conservative SBKF values rather than relying on the conservative values that are typically used.

2. Allowing for hoop stabilization can result in lower cylinder design weights. However, if additional safety is required in a design, a fail-safe pressure-loss load case can be employed and still yield significant weight savings.

3. It is important to take into account the material dimensions in the design of cylinders. Due to manufacturing processes, various alloys may be available in widely different plate stock thicknesses. Therefore, it is important to understand the design drivers. For example, when the design is buckling critical, use of a material that comes in thicker stock can result in significant weight savings. This weight savings arises from the potential for increased stiffener height, which yields more effective stiffeners. The potential weight savings can even be achieved when the thicker plate stock material has what could be deemed as less desirable properties, such as increased density and lower stiffness and strength. 


\section{Tracking \#210774}

\section{References}

${ }^{1}$ Buckling of Thin-Walled Circular Cylinders, NASA SP-8007, National Aeronautics and Space Administration, Rev. August 1968.

${ }^{2}$ Buckling of Thin-Walled Truncated Cones, NASA SP-8019, National Aeronautics and Space Administration, Rev. August 1968.

${ }^{3}$ Isogrid Design Handbook, McDonnel Douglas Astronautics Company, Huntington Beach, Rev. 2004.

${ }^{4}$ Bushnell, David, "PANDA2 - Program for minimum weight design of stiffened, composite, locally buckled panels", Computers and Structures, Vol. 25, No. 4, pp 469-605, 1987

${ }^{5}$ Alcan Data Sheet, 2195 T8R78 - Al-Li Plates, Alcan Aerospace.

${ }^{6}$ Alcan Data Sheet, 2050 T84 Plates, Alcan Aerospace.

${ }^{7}$ Metallic Materials Properties Development and Standardization, MMPDS-04, April 2008, Federal Aviation Administration.

${ }^{8}$ Young, Warren C., Roark's Formulas for Stress and Strain, Sixth Edition, McGraw-Hill Book Company, New York, 1989.

${ }^{9}$ Niu, Michael C. Y., Airframe Stress Analysis and Sizing, Second Edition, Conmilit Press, Ltd., Hong Kong, 1999.

${ }^{10}$ Rankin, Charles C., Brogan, Frank A., Loden, William A. and Cabiness, Harold D., STAGS User Manual, Version 5.0, Lockheed Martin Missiles \& Space Co., Inc., Palo Alto, CA, March, 2003.

${ }^{11}$ Bushnell, David, "BOSOR4: Program for Stress, Buckling, and Vibration of Complex Shells of Revolution", Structural Mechanics Software Series - Volume 1, Edited by N. Perrone and W. Pilkey, University of Virginia Press, Charlottesville, VA, 1977. 